\title{
Digital information technologies for prevention through design (PtD): A literature review and directions for future research
}

DOI:

10.1108/Cl-02-2021-0027

\section{Document Version}

Accepted author manuscript

Link to publication record in Manchester Research Explorer

Citation for published version (APA):

Farghaly, K., Collinge, W., Hadi Mosleh, M., Manu, P., \& Cheung, C. (2021). Digital information technologies for prevention through design (PtD): A literature review and directions for future research. Construction Innovation: Information Process Management. https://doi.org/10.1108/Cl-02-2021-0027

\section{Published in:}

Construction Innovation: Information Process Management

\section{Citing this paper}

Please note that where the full-text provided on Manchester Research Explorer is the Author Accepted Manuscript or Proof version this may differ from the final Published version. If citing, it is advised that you check and use the publisher's definitive version.

\section{General rights}

Copyright and moral rights for the publications made accessible in the Research Explorer are retained by the authors and/or other copyright owners and it is a condition of accessing publications that users recognise and abide by the legal requirements associated with these rights.

\section{Takedown policy}

If you believe that this document breaches copyright please refer to the University of Manchester's Takedown Procedures [http://man.ac.uk/04Y6Bo] or contact uml.scholarlycommunications@manchester.ac.uk providing relevant details, so we can investigate your claim.

\section{OPEN ACCESS}




\title{
Construction Innovation: Information, Process, Management DOI: 10.1108/CI-02-2021-0027
}

Digital information technologies for prevention through design (PtD): A literature review and directions for future research

\author{
Karim Farghaly ${ }^{1 *}$, William Collinge ${ }^{2}$, Mojgan Mosleh², Patrick Manu ${ }^{2}$ and Clara \\ Cheung ${ }^{2}$ \\ ${ }^{1}$ Department of Civil Engineering, Imperial College London, South Kensington Campus, \\ London SW7 2A, United Kingdom \\ ${ }^{2}$ Department of Mechanical, Aerospace and Civil Engineering, The University of \\ Manchester, M13 9LP, Manchester, United Kingdom
}

*Corresponding author.

E-mail addresses: k.farghaly@imperial.ac.uk 


\begin{abstract}
Purpose

With the rapid development of digital information and modelling software applications for construction, questions have arisen about their impact on construction safety. Meanwhile, recognition that designers can help reduce risks involved in construction, operation, and maintenance via a prevention through design (PtD) approach (also known as design for safety), highlights the significance of digital technologies and tools to PtD. Thus, this paper provides a systematic review of a wide range of digital technologies for enhancing PtD.
\end{abstract}

\title{
Design/methodology/approach
}

A 5-staged systematic literature review with coding and synthesis of findings. The review covers journal articles published between 2000 and 2020 related to the applications of various digital technologies, such as building information modelling, 4D, databases, ontologies, serious games, virtual reality and augmented reality, for addressing safety issues during the design phase in construction.

\section{Findings}

Analysis of the articles yielded a categorisation of the digital applications for PtD into four primary areas: (1) knowledge-based systems; (2) automatic rule checking; (3) hazard visualisation; and (4) safety training for designers. The review also highlighted designers' limited knowledge towards construction safety and the possibility to address this by utilising gaming environments for educating designers on safety management and using artificial intelligence for predicting hazards and risks during design stage in a BIM environment. Additionally, the review proposes other directions for future research to enhance the use of digital technologies for PtD.

\section{Originality}

The paper contextualises current digital technology applications for construction health and safety and enables future directions of research in the field to be identified and mapped out.

Keywords: BIM, construction safety, digital design, design for safety, prevention through design, safety management.

\section{Introduction}

Based on the annual statistics report by the United Kingdom Health and Safety Executive (HSE), there were an approximate 42,000 work-related cases of injury in the Great Britain's construction sector during 2019/2020, resulting in significant cost (i.e., GBP $£ 524 \mathrm{~m}$ ) and lost time (i.e. 3.4 million hours) for the sector (HSE, 2020). It has been argued that designers can play a key role in reducing occupational safety and health risks involved in construction, operation, and maintenance works. For example, a survey conducted by Kasirossafar, Ardeshir and Shahandashti (2012) showed that $75 \%$ of respondents believe that most accidents and risks in the construction industry are predictable and therefore can be prevented during the design phase if appropriate tools and technologies are utilised by designers. In this regard, prevention through design (PtD) can be useful as its main aim is to identify occupational safety and health hazards during design and prior to construction to improve working conditions for construction and maintenance personnel (Hardison and Hallowell, 2019).

$\mathrm{PtD}$ is known by many other terms such as safety through design, design for safety, and safety by design. According to Gambatese, Behm and Rajendran (2008), PtD is an element of a holistic approach to minimise risks in construction and enhance workers' safety through hazard prevention. Meanwhile, in several countries, the introduction of regulations has led to health and safety (H\&S) management being 
incorporated into the planning and design stages of construction work, e.g., the Construction Design and Management (CDM) 2015 regulations in the United Kingdom (UK). As a result, safety management is no longer the sole responsibility of the contractor during construction but is also the responsibility of the project client and designer. Although, understandably, not every risk can be addressed or mitigated in the design phase, risk identification at the design phase would help contractors to prepare for those risks well before commencing their work (Yuan et al., 2019). Such an approach would also help to avoid delays that may arise from necessary arrangements in order to prepare for a particular risk during the construction and operation phases (Hossain et al., 2018). The designers' view towards PtD can be classified into three different perspectives (Morrow et al., 2015). Firstly, some designers do not generally address safety issues in their design due to their lack of safety knowledge. Secondly, some designers ask for advice from safety specialists to eliminate risks and highlight ones to be mitigated during the construction and operation stage. Finally, some designers are knowledgeable in identifying and managing risks and are willing to take responsibility towards prevention.

Regardless of their level of expertise in the tacit and explicit PtD-knowledge, designers need training on safety, and digital design tools could be useful in assisting them to address safety issues during the design stage (Che Ibrahim et al., 2021; Schupp et al., 2006). To achieve this, a safety management system (SMS) is acknowledged as crucial for an effective PtD approach. The SMS was first introduced to the construction industry by the European Union in the 1980s. It was intentionally introduced to mitigate hazards and reduce injury risk at construction sites (Vassie et al., 2000); the SMS is designed to: (a) prevent a hazardous event by the elimination of risks; (b) visualise and mitigate the effects of a harmful event, thereby reducing the consequences and/or providing a proper mitigation plan; and (c) achieve a combination of (a) and (b). Despite the growing implementation of several information and communication technologies (ICT) such as Building Information Modelling (BIM) in the whole lifecycle of a building, the adoption rate of BIM and other related digital tools as part of the implementation of a SMS in the design stage is still limited and its full potential is yet to be explored (Jin et al., 2019). A review of existing digital technologies for improving occupational safety and health through PtD is thus both timely and needed. Whilst the recent paper (Akinlolu et al., 2020) provides an overall bibliometric review of emerging research trends in construction safety management technologies, and other review studies (Guo et al., 2017; Liang et al., 2020; Vigneshkumar and Salve, 2020) related to BIM and its applications in construction safety domain, such reviews concentrate more on mitigation of safety and health risks at the construction stage rather than the design stage.

This study goes into a considerably more depth in its systematic analysis and discussion of different digital technologies used during the design and planning phases to mitigate occupational safety and health risk. As such, this study does not offer a narrow focus on BIM technology such as the review (Fargnoli and Lombardi, 2020), but rather also takes into consideration research regarding ontology/database development as well as other digital technologies utilised for PtD such as Virtual Reality (VR), Augmented Reality (AR) and databases. A comprehensive review of previous research can provide great benefits in terms of identifying areas where additional research work is required, and in the process, discerning future directions for development of effective PtD tools. Hence, this paper aims to review the state-of-the-art research and digital tools regarding improvement of construction safety during design stage, whilst suggesting the avenues for future research. To achieve this aim, following research questions are addressed by this research:

1. What digital technologies are utilised for PtD and how have they been applied?

2. What are the challenges in utilising the digital technologies for PtD?

3. What other areas for further development or application of digital tools for PtD could be explored?

The methodological approach adopted for the review is firstly introduced, followed by an analysis of different technologies implemented to improve safety management during design. Different 
applications of the technologies and challenges are then discussed, which leads to a proposed framework for the different applications of digital technologies for effective PtD.

\section{Methodology}

A systematic literature review (SLR) method is adopted in this study, consisting of five main stages (Denyer and Tranfield, 2009; Pawson et al., 2005). Figure 1 illustrates the five stages of the systematic review. In stage 1 , the aforementioned research questions were formulated to direct the study. The second stage involved searching for related articles, while in the third stage preliminary assessment of the selected articles was carried out. Each of these stages consists of three main steps, discussed in the following sub-sections. After the selected articles were identified and extracted, they were coded and synthesised in a fourth stage. From the analysis of the articles, insights regarding the implementation of ICT and their different applications in the design phase for better safety management are discussed. Finally, conclusions are drawn with recommendations for future research.

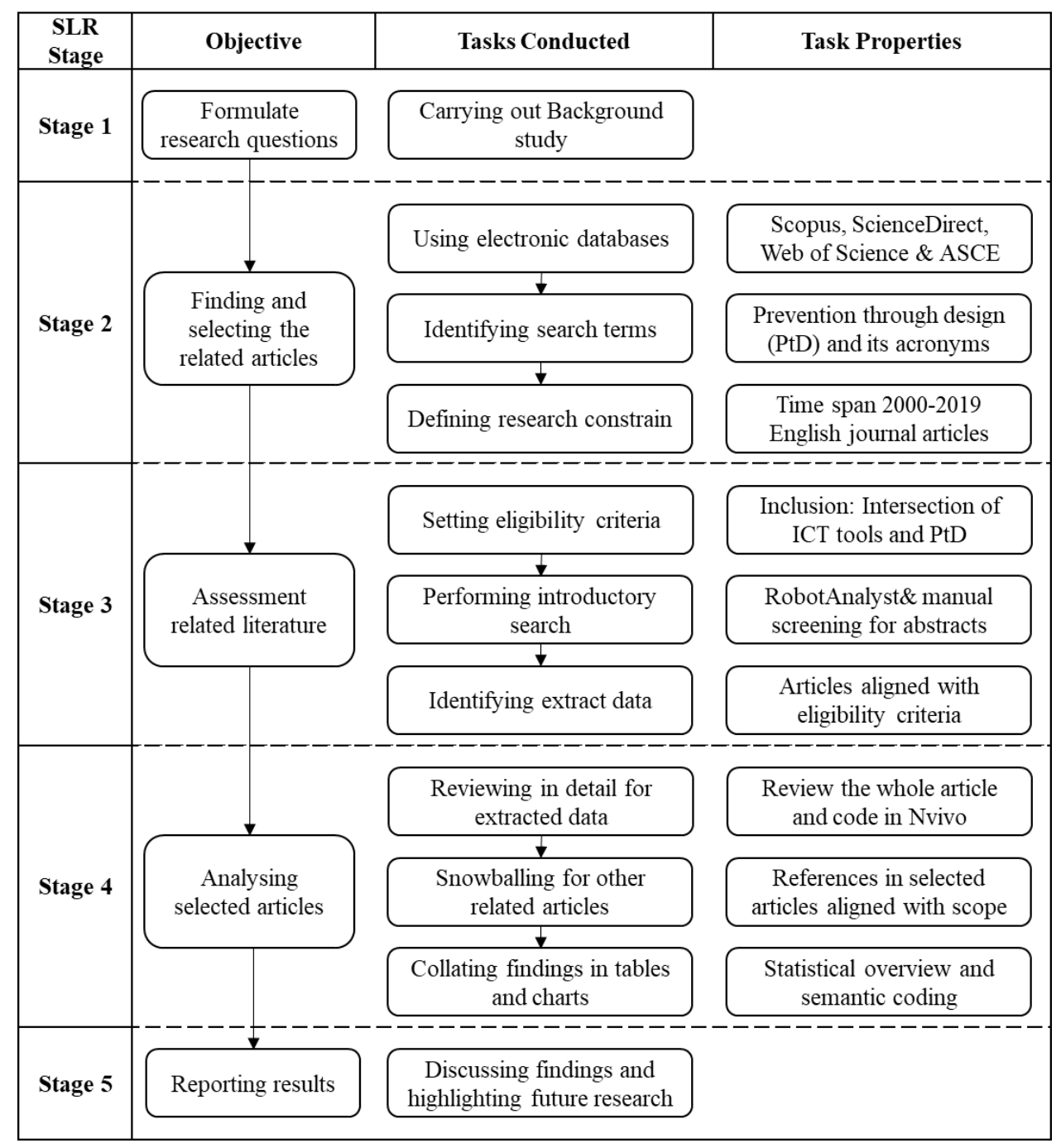

Figure 1: Systematic literature review stages.

\section{Search strategy and eligibility criteria}

For the article search, three databases were selected, namely Scopus, Web of Science, and American Society of Civil Engineers (ASCE) Library. These databases were selected as they have comprehensive coverage of the construction management, built environment, construction informatics and safety 
management domains. The selection of the different databases ensured the systematic inclusion of useful and relevant publications in the field of study, safeguarding that no essential information would be missed. This study considers the intersection of ICT and PtD. To retrieve the literature on ICT for $\mathrm{PtD}$, a set of search commands was applied to verify the papers' titles, abstracts and keywords. The keywords selected for this research is combination of TITLE-ABS-KEY (\{prevention through design\} OR \{design for safety\} OR \{safety construction \} OR \{design risk management\} OR \{safety in design \} OR \{construction safety management $\}$ ) and TITLE-ABS-KEY ( $\{$ BIM $\}$ OR \{Digital Information $\}$ OR \{Technology\} OR \{Ontology\} OR \{Computing\} OR \{Information Management\}). All the search commands were limited to journal articles because they usually provide more comprehensive and higher-quality information, and most systematic reviews in the area of construction management have often used journal articles (e.g. (Manu et al., 2019; Santos et al., 2017)). The digitalization and visualization technologies and techniques started to be implemented and transform the construction safety from the early 2000s; the scope of the literature review reflecting the fact that publications have been generated over the past 20 years (Guo et al., 2017; Hardison and Hallowell, 2019). The search commands were limited time span from 2000 till 2020 in order to cover recent studies in the last two decades. The search command was also limited to English language. After removing the duplications of journal articles extracted from the three different databases, 277 articles were identified.

\section{Selection and Review Steps}

The selection process illustrated in Table 1, consists of two main steps. Firstly, selection through title, abstract, keywords and subsequently through the contents of the article. The first step was achieved using a text mining and machine learning tool, RobotAnalyst, to select relevant articles and to provide an inclusion confidence rate (further explanation of the tool is provided in the following sub-section Analysis tools). The results were validated manually and any excluded articles in this step were removed without scanning the full text. The validation required double screening of each abstract of the 277 papers to identify their eligibility to answer the research questions. Then, the two authors meet to share and discuss their decisions and reconcile disagreements. Finally, the whole team analysed the process and decisions after screening has been completed. Whilst screening of the abstracts was performed manually by the authors, a further benefit of utilising Robotanalyst was its` capability of clustering abstracts based on several keywords/terms, enabling the users to find more relevant references to systematically review together (Farghaly, 2019). On the other hand, any included articles underwent a full-text review. The relevant articles were classified and coded to answer the research questions stated in the introduction section, while the irrelevant ones were excluded after the review. The Snowball technique was utilised to minimise the probability of missing relevant publications. Snowballing refers to utilising the references of an included article for review to identify other relevant articles to be added for the systematic review (Booth et al., 2016). The same criteria utilised for the selection was adopted for snowballing which led to inclusion of an additional seven articles (see

Table 1).

Table 1: Article selection process for systematic review

\begin{tabular}{|c|c|c|c|c|}
\hline Selection steps & In & Included & Excluded & Out \\
\hline \multicolumn{5}{|l|}{ Review title, abstract and keywords } \\
\hline First scanning - RobotAnalyst & 277 & - & 196 & 83 \\
\hline Second scanning - RobotAnalyst & 83 & 6 & 33 & 56 \\
\hline Manual scanning & 56 & 6 & 4 & 58 \\
\hline \multicolumn{5}{|l|}{ Review the whole article } \\
\hline Detail Review & 58 & - & 11 & 47 \\
\hline
\end{tabular}




\section{Analysis tools}

The selected articles based on the search commands were first imported to Endnote (Reference Manager Software). Several queries were performed to remove any duplications and to better understand the properties of the articles such as the most frequent journals and year of publications. Subsequently, an RIS file was exported including all the references and imported to RobotAnalyst. RobotAnalyst is a web-based platform where Machine Learning (ML) and Text Mining (TM) are utilised to screen reference collections obtained from literature database queries (Przybyła et al., 2018). Robotanalyst is a supervised learning system and its inclusion and exclusion confidence is provided by a binary classification model that updates after each screening. o optimize performance, two manual screenings were conducted to train the machine and improve the accuracy of the results. After training RobotAnalyst tool by manually reviewing sample articles and classifying them as included and excluded articles, 83 journal articles from the total of 277 were identified as included references in the first round. Furthermore, random manual screening was performed on the included and excluded articles to evaluate the accuracy of decision making. The second round identified 6 articles relevant to the intersection of ICT and PtD domain, with 33 being irrelevant. Finally, a second manual screening of the 56 included abstracts was performed to evaluate the machine results. Based on the research team's evaluation using the articles' title and abstract, $95 \%$ of the RobotAnalyst analysis were identified as correct categorisation. The 58 articles related to the research aim and questions were then downloaded and attached to the references in the Endnote platform. These articles were exported as an Endnote library and imported into QSR Nvivo 12 platform, where coding, classifying, and clustering of the articles took place. NVivo enables coding for different articles to be represented visually, with networks and connections between articles to be identified (O'Neill et al., 2018). The articles were coded across several aspects such as digital technologies implemented, research topic/focus area of the article, and challenges related to the implementation of the technologies. The coding was a mix of concept-driven coding and data driven coding. The concept-driven coding was utilised for codes related to technology and risk type, while data-driven coding was utilised for the other aspects. During this stage, 11 papers were excluded, and eight papers were added through the snowballing. 55 articles were analysed and discussed further in the analysis of articles section below. Figure 2 presents an example of the codes assigned to the reviewed articles. 


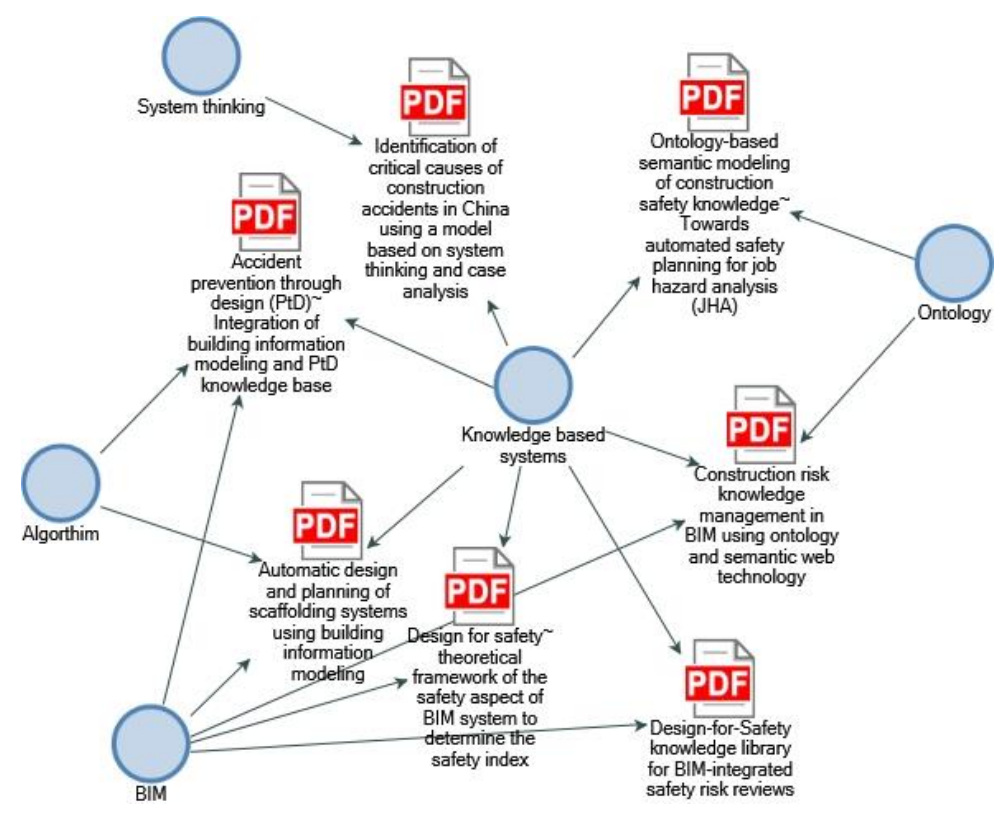

Figure 2: Nvivo Screenshot representing example of coding.

\section{Bibliometric analysis results}

\section{Distribution of publications by year}

The numbers of annually published articles addressing implementation of ICT for PtD are summarized in Figure 3. Overall, the results show that the topic has been of increasing interest to researchers since 2012 , with the number of publications reaching a peak of 10 articles (19\%) in 2019. More than $85 \%$ of the papers were published in the time span from 2012 till 2020. The possible explanation for such a trend could be due to the growing adoption of advanced digital technologies in the construction industry, such as text mining, NoSQL databases and BIM for clash detection (Tixier et al., 2017), scheduling, and asset management (Farghaly et al., 2019). The trend of AI and digital transformation has increased significantly jumping form 1370 papers in 2010 to 5605 papers in 2018 (Darko et al., 2020). Moreover, the reduction of 2020 articles could be the construction informatics committee's concentration on the effect of the pandemic on the Architecture, Engineering and Construction (AEC) sector and how to overcome that with the digital transformation. Several work was published in the last couple of years concentrating on the new measurement during the construction stage to enhance safety in the era of post-COVID (Alsharef et al., 2021; Araya, 2021; Megahed and Ghoneim, 2021). 


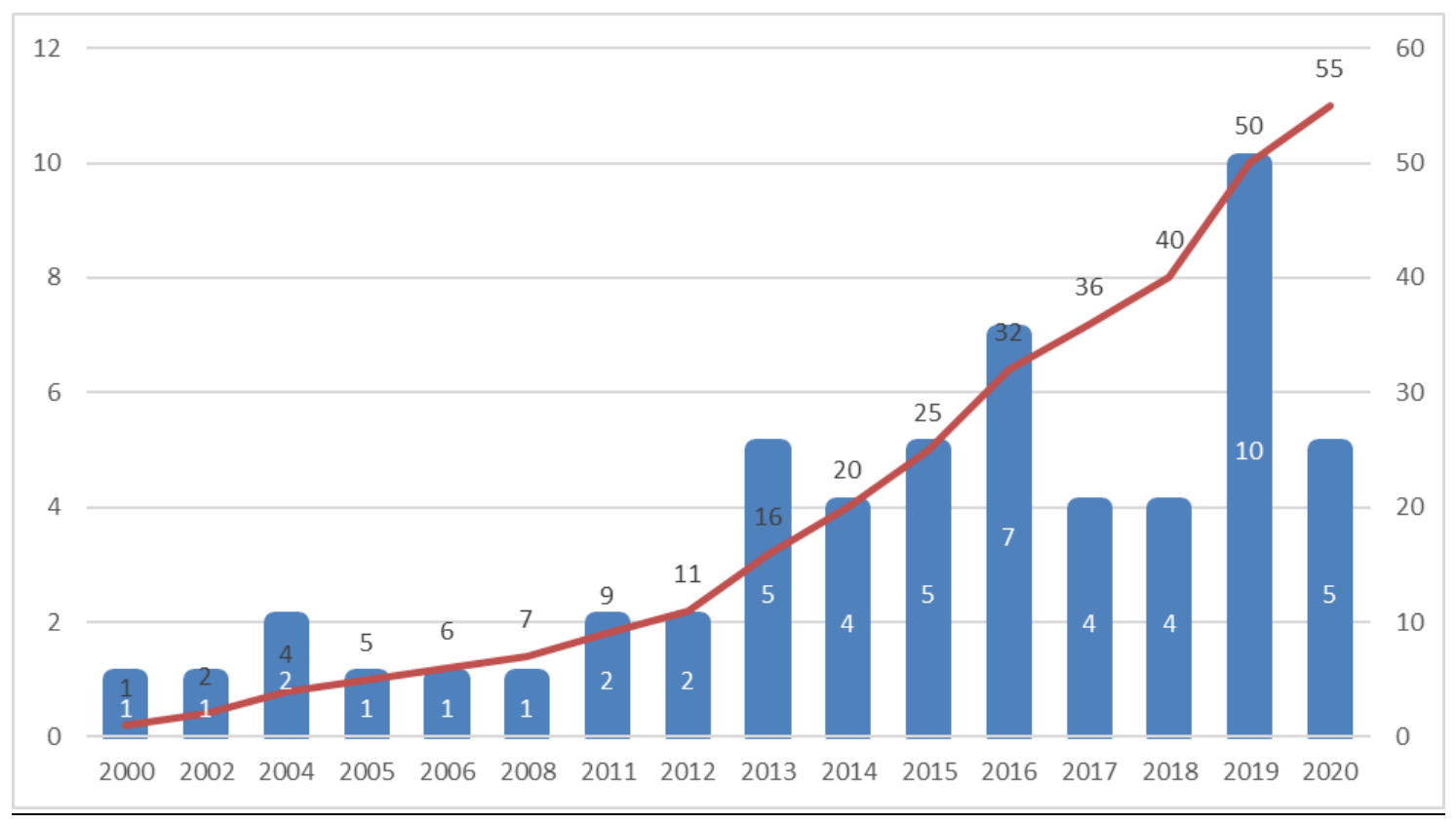

Figure 3: Number of Articles by year of publication and their cumulative since 2000.

\section{Distribution of publications by digital technologies and research topic/focus area}

To assist understanding of how the tools and techniques relate to each of the four categories of applications discussed in the next section, Figure 4 provides a visual reference for the tools and techniques and number of articles implemented these tools and techniques and for which application. It indicates how BIM technologies dominate the discourse on PtD applications and research, with databases, algorithms and cloud computing coming in second and third places. Such a trend may be expected as BIM has become the new international benchmark for better efficiency and collaboration in the construction sector as well as in operation and maintenance (O\&M) of built assets (Farghaly et al., 2019).

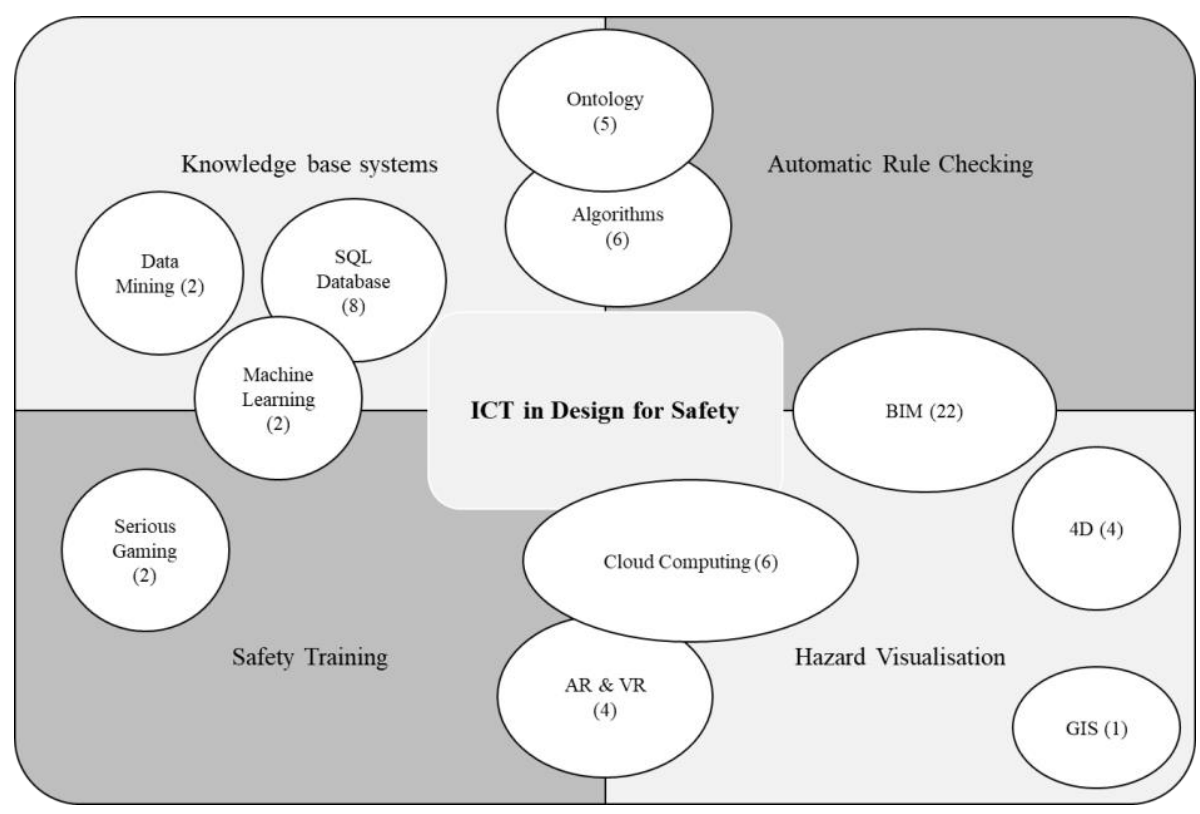

Figure 4: Article distribution by technology implemented and applications. 


\section{Analysis of Articles}

A further analysis of the articles' content allows exploration of both the technologies adopted to enhance construction safety during design, and the challenges of implementation.

\section{Application of Digital technologies for PtD}

Broadly, the literature (Hadikusumo and Rowlinson, 2004) recognises that PtD tools should aim to cover one or more of the following key activities:

1. Capturing required knowledge related to construction hazards and safety measures to eliminate or mitigate associated risks.

2. Assisting designers to identify and visualise safety hazards in construction projects.

3. Training designers to identify hazards and mitigate them using safety measures.

Consequently, the digital technologies for PtD in the literature were classified into the following four categories of applications, namely, knowledge base systems, automatic rule checking, hazard visualisation, and safety training. Table 2 presents the reviewed articles (55 in number as indicated in

Table 1) and how these four categories are covered in each article. Each of the categories is then discussed in detail.

Table 2: Selected articles and the applications covered in each article

\begin{tabular}{|c|c|c|c|c|c|}
\hline Article Reference & Year & KBS & ARC & HV & ST \\
\hline \multicolumn{6}{|c|}{ Knowledge Base System } \\
\hline Kim and Teizer, 2014 & 2014 & Yes & Yes & Yes & - \\
\hline Teo et al., 2016 & 2016 & Yes & Yes & Yes & - \\
\hline Hossain et al., 2018 & 2018 & Yes & Yes & Yes & - \\
\hline Yuan et al., 2019 & 2019 & Yes & Yes & Yes & - \\
\hline Lee et al., 2020 & 2020 & Yes & Yes & - & - \\
\hline Hadikusumo and Rowlinson, 2004 & 2004 & Yes & - & Yes & - \\
\hline Guo et al., 2013 & 2013 & Yes & - & Yes & Yes \\
\hline Choe and Leite, 2017 & 2017 & Yes & - & Yes & - \\
\hline Rodrigues et al., 2020 & 2020 & Yes & - & Yes & - \\
\hline Cameron, 2000 & 2000 & Yes & - & - & - \\
\hline Hadikusumo and Rowlinson, 2002 & 2002 & Yes & - & - & - \\
\hline Park and Park, 2004 & 2004 & Yes & - & - & - \\
\hline Behm, 2005 & 2005 & Yes & - & - & - \\
\hline Carter and Smith, 2006 & 2006 & Yes & - & - & - \\
\hline Cooke, 2008 & 2008 & Yes & - & - & - \\
\hline Wang et al., 2011 & 2011 & Yes & - & - & - \\
\hline Behm and Choon Hock, 2012 & 2012 & Yes & - & - & - \\
\hline Hsueh et al., 2013 & 2013 & Yes & - & - & - \\
\hline Chi et al., 2014 & 2014 & Yes & - & - & - \\
\hline Chi et al., 2015 & 2015 & Yes & - & - & - \\
\hline Kumar and Cheng, 2015 & 2015 & Yes & - & - & - \\
\hline Zhang, Sulankivi, et al., 2015 & 2015 & Yes & - & - & - \\
\hline Ding et al., 2016 & 2016 & Yes & - & - & - \\
\hline Malekitabar et al., 2016 & 2016 & Yes & - & - & - \\
\hline Manu et al., 2016 & 2016 & Yes & - & - & - \\
\hline Moura et al., 2016 & 2016 & Yes & - & - & - \\
\hline Tixier et al., 2017 & 2017 & Yes & - & - & - \\
\hline Zou et al., 2017 & 2017 & Yes & - & - & - \\
\hline Teja Swaroop et al., 2018 & 2018 & Yes & - & - & - \\
\hline Shen et al., 2019 & 2019 & Yes & - & - & - \\
\hline Su et al., 2019 & 2019 & Yes & - & - & - \\
\hline Xing et al., 2019 & 2019 & Yes & - & - & - \\
\hline Zhang, Zhang, et al., 2019 & 2019 & Yes & - & - & Yes \\
\hline
\end{tabular}




\begin{tabular}{|c|c|c|c|c|c|}
\hline Zhang, Zhu, et al., 2019 & 2019 & Yes & - & - & - \\
\hline Zhou et al., 2019 & 2019 & Yes & - & - & - \\
\hline Hare et al., 2020 & 2020 & Yes & - & - & - \\
\hline \multicolumn{6}{|c|}{ Automatic Rule Checking } \\
\hline Melzner et al., 2013 & 2013 & - & Yes & Yes & - \\
\hline Park and Kim, 2013 & 2013 & - & Yes & Yes & - \\
\hline Zhang et al., 2013 & 2013 & - & Yes & Yes & - \\
\hline Kim et al., 2020 & 2020 & - & Yes & Yes & - \\
\hline Qi et al., 2014 & 2014 & - & Yes & - & - \\
\hline Zhang, Boukamp, et al., 2015 & 2015 & - & Yes & - & - \\
\hline Kim et al., 2018 & 2018 & - & Yes & - & - \\
\hline Schwabe et al., 2019 & 2019 & - & Yes & - & - \\
\hline \multicolumn{6}{|c|}{ Hazard Visualisation } \\
\hline Kiviniemi et al., 2011 & 2011 & - & - & Yes & - \\
\hline Kim et al., 2012 & 2012 & - & - & Yes & - \\
\hline Azmy and Mohd Zain, 2016 & 2016 & - & - & Yes & - \\
\hline Edirisinghe et al., 2016 & 2016 & - & - & Yes & - \\
\hline Tymvios, 2017 & 2017 & - & - & Yes & - \\
\hline Golabchi et al., 2018 & 2018 & - & - & Yes & - \\
\hline Jin et al., 2019 & 2019 & - & - & Yes & - \\
\hline Hardison et al., 2020 & 2020 & - & - & Yes & - \\
\hline \multicolumn{6}{|c|}{ Safety Training } \\
\hline Albert et al., 2014 & 2014 & - & - & - & Yes \\
\hline Din and Gibson, 2019 & 2019 & - & - & - & Yes \\
\hline Kamardeen, 2015 & 2015 & Yes & - & - & Yes \\
\hline Park et al., 2015 & 2015 & Yes & - & - & Yes \\
\hline
\end{tabular}

Notes: KBS= knowledge base system; ARC = Automatic Rule Checking; HV= Hazard Visualisation; ST= Safety Training

\section{Knowledge base systems}

A PtD knowledge-based system should ideally provide the foundational information to enhance the PtD competence of designers. To generate knowledge systems, field experts, facts and observations have to be integrated together as a result of collecting, filtering, comparing, and analysing available information to generate expressive outcomes. In the construction industry, knowledge bases of health and safety information can be created and managed by individual companies with an interest in health and safety or governmental bodies in charge of overseeing health and safety activities (e.g., the Health and Safety Executive in the UK). Traditionally, PtD relies on tacit knowledge combined with companies' policies and documents (Choe and Leite, 2017), while, other forms of knowledge, such as domain knowledge from regulations, guidelines and explicit knowledge from government databases may be less utilised. This lack of integration between various sources of knowledge can hinder the mobilisation of effective PtD knowledge base systems. To address this gap, several research works have been conducted to develop a safety knowledge base system for both explicit and domain knowledge (Ding et al., 2016; Hossain et al., 2018; Zhang, Zhu, et al., 2019). The outcome can be classified into three fundamental areas, namely, knowledge acquisition, knowledge management, and expert systems. These are now considered in turn.

Knowledge acquisition systems aim to improve the ill-structured stored information related to safety risks by collecting and clustering information into ordered formats and analysing available databases. In the early days of PtD implementation, a bottom-up method to improve safety identification especially in projects with insufficient safety data (Wang and Ruxton, 1997). Based on such a method, the DFSP tool (Hadikusumo and Rowlinson, 2004) and Total-Safety (Carter and Smith, 2006) were developed to help engineers produce construction method statements with high levels of hazard identification. Hossain et al. (2018) developed a design for safety (DfS) knowledge library structured into a 6-level hierarchical taxonomy to better capture the safety knowledge. Their taxonomy starts with the design topic, followed by the design element, work activity, constraint, safety risks and finally DfS required design features. Other systems and databases have also been developed to identify possible safety hazards and accident precautions (Hadikusumo and Rowlinson, 2002), environmental and human risk factors (Chi et al., 2015), and near-miss information (Zhou et al., 2019). 
Regarding the knowledge management facet of knowledge base systems, to share the retrieved information, efforts have been made to bring the ontology concept to the construction safety domain. An ontological approach offers a way to integrate and map the different datasets from the different sources and potentially enhance collaboration between the different stakeholders responsible for better construction safety. As noted by Ding et al. (2016), an ontology can offer three main benefits in knowledge modelling and management: 1) improve model flexibility and extendibility; 2) provide a robust semantic representation; and 3) enhance knowledge retrieval by improving the retrieval requests from the concept level. Several ontologies have been proposed in the literature for safety information sharing and job hazards. For instance, Zhang, Boukamp, et al. (2015) developed an ontology for job hazard analysis for improving construction safety knowledge management in BIM environments. Their developed ontology provides a potential link between safety risk knowledge and the BIM elements by mapping the developed ontology classes with the IfcOwl classes. The IfcOwl is the approved ontology by BuildingSMART to represent the Industry Foundation Classes (IFC) schema. Other works have been conducted for the same purpose, such as by Ding et al. (2016) to link risk knowledge with related building objects in a BIM environment using ontology-based methodology. Ding et al. (2016) modelled risk knowledge into an ontology-based semantic network to produce a risk map from which interdependencies between risks can be inferred semantically. Based on this semantic retrieval mechanism, the applicable knowledge is then dynamically linked to specific objects in the BIM environment. Similarly, Wang and Boukamp (2011) proposed a corresponding representation and reasoning framework, and Xing et al. (2019) developed a domain ontology (SRI-Onto) to retrieve safety risk knowledge in metro construction project. This developed ontology consists of seven main classes namely, project, construction activity, risk factor, risk, risk grade, risk consequence, and risk prevention measure. Nevertheless, the existing safety ontologies should be validated through case studies and performance evaluations.

The third aspect of safety knowledge base system is expert systems. Expert systems utilise knowledge retrieved from knowledge accumulation and management work and use artificial intelligence (AI) and "what if" scenarios to provide suggestions for designers related to health and safety. These systems can highlight issues related to traceability of design data (Park and Park, 2004), method statements (Carter and Smith, 2006), vegetated roofs (Behm and Choon Hock, 2012), and site layout planning (Kumar and Cheng, 2015). More recent work has brought together expert systems and the KBS concept into an overall systems architecture. Yuan et al. (2019) present a complete prototype knowledge base system for the detection of safety risks that combines a Prevention through Design (PtD) knowledge base, connected to a BIM environment via a Plug-In. The Plug-In sends feedback to designers through popup alert windows containing construction risk identification numbers (IDs) and corresponding precontrol measure IDs in a Revit model. The Plug-In functions through an automated rule-based algorithm that extracts rules from guidance/regulations, using data from the Revit model. The prototype system was tested on a case study project and was verified by professional practitioners as effective and efficient. Yuan et al.'s (2019) study makes an important contribution by integrating BIM, PtD database, Plug-In and a case study project with designers. Several work has utilised the same approach (Kim et al., 2020; Rodrigues et al., 2020).Other expert systems are discussed in the next section as they overlap with the automatic rule checking of design.

\section{Automatic rule checking}

One of the main applications of ICT in the construction industry is to evaluate building designs against required regulations and codes of practice. This occurs through facilitating various rule checking and simulations. A rule-based checking system refers to a software that evaluates the design of a building based on configured building regulations (Eastman et al., 2009). In other words, the purpose of automatic rule checking systems is to encode rules and criteria by interpretation and then checking of the design against these machine-read rules automatically. Eastman et al. (2009) introduced rule checking in the digital BIM environment and structured the development into four main steps: (1) rule 
interpretation; (2) building model preparation; (3) rule execution; and (4) reporting of checking results, resulting in the conclusion statements: "Pass", "Fail", "Warning", "Not Applicable" or "Unknown". Traditionally, design evaluation against health and safety rules and regulations is performed manually by health and safety experts and not by designers probably due to limited health and safety knowledge of the designer. This traditional approach is time-consuming, expensive and error-prone (Zhang et al., 2013) (Zou et al., 2017). Several researchers have developed rule checking systems to overcome this obstacle. For instance, Zhang et al. (2013), Melzner et al. (2013) and Zhang, Boukamp and Teizer (2015) proposed a safety rule checking method for protection against falling from height during the design phase. The proposed safety rule checking framework contains rules for checking building features such as holes, edges, and slab openings against fall protection regulations. They transformed the rules into a Plug-In on an existing BIM platform (Revit) to check BIM models against the rules and to generate automatic quantity take-off for guardrail system and hole covers required to eliminate fall risks. Qi et al. (2014) also developed a set of rules for fall protection using two building model checking platforms: Solibiri Model Checker; and BIMServer. Yuan el al. (2019) developed a set of rule checking commands by analysing safety regulations through keywords such as "should", "should not" and "must". This set of rules were transformed into a Revit Plug-In and ran against the design model to highlight the safety hazards and recommend proper mitigation plans to eliminate or at least mitigate these risks. Apart from the application of rule checking based on safety regulation, the same method can be applied to other scenarios/areas such as scaffolding construction (Kim and Teizer, 2014), clash detections (Teo et al., 2016), temporary structures (Kim et al., 2018), construction site layout planning (Schwabe et al., 2019) and DfS Knowledge Library (Hossain et al., 2018).

\section{Hazard visualisation}

In the area of hazard visualisation, several studies have been conducted and several industry applications have been developed due to BIM capabilities in visualisation. Visual technologies such as BIM, AR and VR offer a 3D environment instead of 2D drawings and documents where the required PtD information such as high-risk tasks (Jin et al., 2019), temporary structures (Kim and Teizer, 2014), safety programs (Teo et al., 2016), safety and productivity of labour operations (Golabchi et al., 2018) and job hazard area (JHA) (Zhang, Sulankivi, et al., 2015) can be identified and managed. A JHA refers to an area where a potential job hazard can lie such as holes, edges and temporary structures. Kim et al. (2012) utilised AR for visualisation of construction equipment and highlighted that this approach can help users to select the best crane choice that is optimised in terms of efficiency and safe operation as the construction progress is changing. Besides the implementation of BIM and AR for enhancing safety management through visualisation, a new approach called infographic was suggested for visualising wicked problems (i.e. highly complex problems) (Edirisinghe et al., 2016). On the other hand, Guo et al. (2013) proposed a new framework for the implementation of virtual prototyping (VP) to model and simulate construction to aid safety management. The main beneficiaries of using it are project managers, safety managers and site workers. However, such frameworks are still at a conceptual stage and need to be further developed. Additionally, it has been argued that 3D visualisation alone cannot identify all potential hazards. For example, several collisions can take place due to improper construction planning and can be eliminated by changing construction schedules and/or construction methods. 2D drawings or 3D models may not provide a proper visualisation to identify and manage potential hazards. To address this, 4D technology can be implemented along with 3D during the preconstruction stage. Most of the academic works in this area have focused on the construction phase, with little attention to the design and/or pre-construction stages. Teo et al. (2016) presented a pre-project planning feature as part of their framework for a tool. Using this feature, designers and project managers can visualise the possibility of occurrence of any hazard during any construction activities. Jin et al. (2019) also employed BIM, scheduling and risk tools to propose a method for schedule-risk integration in the design phase. This proposed method provides risk simulation and visualisation in which the designers can distinguish high-risk tasks and associated work areas. They recommended that the method can only be beneficial in design-build procurement methods as the contractor's engagement and input are vital (Hare 
et al., 2020; Jin et al., 2019). The number of design elements considered was limited in their study and therefore it is vital to consider a wider range of design elements and quantify their associated risks for future applications. In addition, the actual impacts and benefits of such applications are yet to be investigated and proven.

\section{Safety training}

It is recognised that considering safety in design is essential for construction safety. For example, the National Institute for Occupational Safety and Health (NIOSH) workshop held in 2007 in USA stressed enhancing the knowledge of designers for worker safety and health considerations through better education and training (Sacks et al., 2015). In addition, the UK Construction Design and Management Regulations 2015 (CDM 2015) requires that designers must have the skills, knowledge and experience in order to perform their design function in a manner that protects the safety and health of workers (HSE, 2015). Against this backdrop, education and training are two of the most noteworthy factors that influence successful implementation of Prevention through Design (PtD) (Manu et al., 2016, 2019). It has been also noticed that education should target inexperienced designers and engineering students (Mann III, 2008). Using simulations and computer games to learn PtD was found to be a more effective way of safety training in different sectors, such as aviation, mining and offshore gas sectors than using in-class lectures (Din and Gibson, 2019; Park et al., 2015). Such findings are promising and show that researchers could examine in detail how to adopt these technologies for enhancing PtD safety training for designers in the construction industry. For example, Albert et al. (2014) showed that there are potential benefits of using serious gaming concepts and augmented virtual environments in occupational health and safety training. They proposed a framework called SAVES to train construction workers in hazard recognition using serious games and augmented reality platforms. Other web-based platforms and mobile applications have been developed to educate construction workers about PtD principles. These applications include Design Support System (Cameron, 2000), web-based CSMIS platform for effective identification of risks (Park et al., 2015), and Fall PtD phone application (Kamardeen, 2015).

Limited research has focused on improving the safety training of designers and design students. The reason may be that the value of PtD education has not been fully recognized. Among the limited research, Din and Gibson (2019) developed a computer-based serious game to teach hazard identification and safety measures to construction engineering and management students. The game includes scenarios in which students can increase their awareness of safety. The topics used for creating scenarios include site location and access, material storage options, housekeeping, use of personal protective equipment and parapet adequacy for fall protection. These scenarios were adapted from the Construction Industry Institute's tool developed by Gambatese and colleagues in 1997. In view of this, future research could investigate the mechanisms of providing effective PtD training to designers or design students based on these findings.

\section{Implementation challenges}

Despite the potential benefits of digital technologies for PtD (e.g., for hazard visualisation and automatic safety rule checking (Guo et al., 2013; Zhang, Sulankivi, et al., 2015), overall effectiveness of using available tools and technologies for better safety management in the design stage is still not fully established. The adoption of SMS incorporates a range of risks including management risk, financial risk and legal risk. As in any adoption of new technology or systems, the staff/designers can get confused over new processes and duties, and get overloaded with work (Kaushik et al., 2014). Consequently, they can struggle with change and resist new technology. Therefore, the change should be managed carefully from a high managerial level following best practices to ensure effective training takes place for everyone in the team. Since the construction industry is known for being slow at embracing technology (Davis and Songer, 2008), and the value of PtD is not fully recognized by some professions, the company management may favour current approaches instead of investment in new approaches (Din and Gibson, 2019). Therefore, the return on investment and cost-saving analyses 
should be clearly conducted to determine the best practices to technologies adoption for safety management (Mohammadi et al., 2018). Finally, implementation of SMS requires collaboration and information sharing between different project stakeholders, potentially raising legal and cybersecurity concerns and problems with ownership of data/design and liabilities of errors in the design models. Therefore, regulations and guidance should be stated in the very early stages of a project to track and control errors and make decisions regarding responsibilities (Ghaffarianhoseini et al., 2017). Once these risks are mitigated and designers are encouraged to implement PtD with the aid of digital technologies, further challenges may arise during the implementation stage such as scalability, inadequate quality of design models, and construction sequencing. These are further discussed below.

\section{Scalability}

Scalability of workable solutions for industry use is a significant barrier to be overcome in the application of digital technologies for PtD. The works published in the field (e.g. Hossain et al. (2018); Yuan et al. (2019); Zhang et al. (2019)) provide tangible but limited validation of the PtD concept in BIM environments. Such works are limited in terms of scalability. For example, most of the solutions proposed are trying to address one risk type only - usually falling from height (Qi et al., 2014; Zhang et al., 2013; Zhang, Sulankivi, et al., 2015) and these solutions are not suitable for other occupational health and safety risks such as manual handling, noise and hazardous substances. Other solutions are only suitable for regular buildings and require developing more comprehensive rules to implement checks on complex buildings (Kim and Teizer, 2014), while other solutions concentrate on risks related to a limited number of design elements (Jin et al., 2019; Kim et al., 2020) and/or limited to a specific BIM platform (Rodrigues et al., 2020).

\section{Inadequate Quality of Models}

Inadequate quality of digital design models imposes a further challenge in the application of digital technologies for PtD. Most BIM models today lack standardisation, use proprietary formats, have low detailing and are often not kept up to date in the construction phase (Teizer and Melzner, 2018). The data provided to the evolving BIM model must be accurate and up to date, otherwise, the digital model will not reflect the reality confronting designers engaging with the model for health and safety purposes. A carefully managed periodic uploading of new data from different parties following an agreed information cycle (enshrined in a BIM Execution Plan) is one way to avoid inadequate quality of design models from adversely affecting identification of health and safety problems. An associated issue is understanding of the spatio-temporal relationship of workspace and time which can be enabled by BIM. As Teizer and Melzner (2018) note, many decision-makers have yet to adapt to the full potential of three-dimensional (3D) and time-based visualisation/simulation (4D) of information models. For many safety engineers who are used to applying their spatial imagination to understand the coherent structure of a building, BIM offers a new way to engage with the identification of health and safety problems. However, training, education and experience in using BIM for this work is a barrier to implementing PtD. Provision of adequate training and education for enhanced use of BIM in the design phase and safety work would require more investment in the front-end of a project, something clients may resist. Large parts of the construction workforce are not prepared in adapting to new technologies or new processes. Therefore, the benefits and gains of PtD and the role of BIM in the process needs to be understood by the industry. The mitigation of risk in the design phase can only effectively happen with client buy-in, planners and designers designing out hazards, as well as contractors, subcontractors and safety equipment suppliers collaborating through advanced workflow management (Kim et al., 2020; Lee et al., 2020; Teizer and Melzner, 2018).

\section{Construction Sequencing}

Traditional safety planning approaches and 3D building information models rely on static building information only. As a result, the site-specific dynamic information such as the construction sequence for erecting and installing the building elements, which can be vital for effective PtD, are not taken into 
consideration (Choe and Leite, 2017). Meanwhile, this complexity and dynamic nature of the construction industry and its on-site work patterns are mainly the reasons behind the existence of hazards (Zhang, Sulankivi, et al., 2015). In addition, it would be beneficial for any PtD application to visualise the construction sequence based on the schedule and associated hazards and locations to promote safety awareness and communication between stakeholders. Therefore, the availability of information related to construction sequencing in an early stage is crucial for effective $\mathrm{PtD}$ by designers (Jin et al., 2019; Rodrigues et al., 2020). For example, early engagement from contractor and subcontractor teams and providing the procurement methodologies and construction or installation plans can be beneficial for better PtD.

\section{Proposed framework for enhancing application of digital technologies for PtD}

The reviewed papers show that digital technologies could be helpful to designers in implementation of $\mathrm{PtD}$ on projects. Also, the review reveals evidence of the growing interest in digital design for more effective PtD. However, the literature about further development of the subject is still limited; most research concentrating on only one application and/or one risk type. To help bridge this knowledge gap, an integrated framework (Figure 5) is proposed that situates the different applications of ICT to improve $\mathrm{PtD}$ based on the discussion presented in previous sections. The framework proposes seven different applications where ICT can be implemented for effective PtD and identifies areas for future research. The proposed applications are aligned with the risk information cycle (identify, use, share and generalise), as indicated in PAS 1192-6 (2018) and shown in Figure 5.

A knowledge base system is at the core of the possible applications; this component being central to a successful implementation where the required information related to safety management can be stored and linked to other datasets. The knowledge base system should be developed taking into consideration both explicit and tacit datasets from databases such as those of health and safety regulators (e.g. the UK Health and Safety Executive), and standards and regulations (e.g. CDM 2015 and PAS 1192-6). Once a knowledge base system has been developed, there are two different directions to help designers to effectively implement PtD on projects: 1) competence development applications; and 2) design function applications (as indicated on Figure 5).

The competence development applications (left hand-side of the framework) provide tools to educate and train designers to effectively prepare designs (including digital design models) while considering safety management. In other words, competence development applications enhance designer's PtD knowledge and skills which would be reflected in the way they design. The competence development applications cover three applications: namely, hazard identification, mitigation plans, and training using serious games. In hazard identification applications, relationships between the hazards, activities and building elements should be identified. For example, the hazard related to falling from open edges should be linked to the slab with openings and the associated construction activities such as installation and loading and unloading materials. Aligned to this, researchers have developed taxonomies and ontologies to illustrate the relations between hazards, elements, locations and activities (Ding et al., 2016; Hossain et al., 2018; Xing et al., 2019; Zhang, Sulankivi, et al., 2015). Such taxonomies and ontologies could be leveraged in developing hazard identification applications. Beyond hazard identification, few researchers recommend mitigation plans (i.e. measures) for addressing the identified hazards. Moreover, future work is required to cover a broader range of scenarios and risk types rather than concentrating on one risk type. Once hazards are identified and the proper mitigation/treatment plans for each hazard are determined, the development of training tools for designers to get familiar with hazards in a BIM environment could be beneficial. For developing this kind of training tool for designers, several technologies such as gaming engines, VR and AR could be utilised due to their visualisation capabilities. 
The design function applications (right hand-side of the framework) assist designers to effectively incorporate PtD solutions during the process of preparing designs. These applications would include hazard visualisation, automatic rule checking, and risk prediction programmes. Hazard visualisation in a 3D environment for improving $\mathrm{PtD}$ has been a growing research area in recent years due to BIM capabilities. Meanwhile, it has been emphasized that 3D models alone cannot identify all potential hazards. The timeline of the project and the construction sequence are crucial to identify the hazards during the preconstruction stage (Jin et al., 2019; Rodrigues et al., 2020), and hence PtD technologies should integrate construction sequencing information. Regarding the second aspect of the design function applications shown in figure 5 (i.e., automatic rule checking), more rules need to be developed in this area as most research to date have only concentrated on one type of hazard - fall from height. Finally, the risk prediction applications utilising machine learning and artificial intelligence should be another future research direction.

The proposed framework is based on a review of literature relating to applications of various digital technologies addressing safety issues during the design phase in construction: this literature adopts a traditional view of safety management, often referred to as Safety I, where the objective is to ensure unwanted outcomes, incidents and accidents are minimized. An alternative approach to understanding safety, known as Safety II, engages with construction projects as complex socio-technical systems, where human adjustments are particularly significant (Sujan et al., 2017). This review did not review Safety II approach in literature due to the limited papers utilising that approach and in parallel discussing digital information. This paper is a part of ongoing research adapting the two approaches (Safety-I and Safety-II) to develop a platform for better PtD (Collinge et al., 2020).

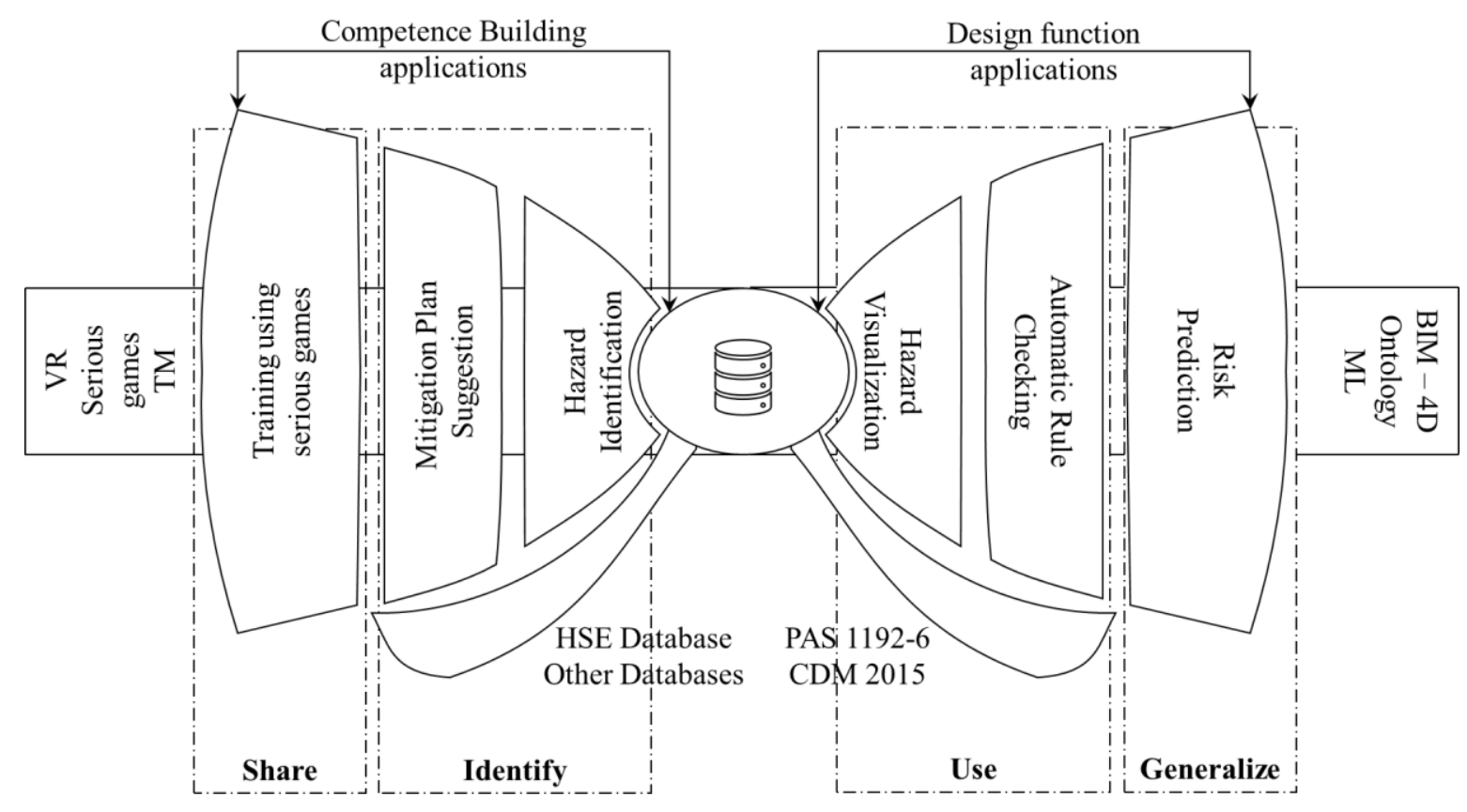

Figure 5: Integrated framework of application of ICT for PtD

\section{Conclusions}

The systematic review of the literature of the past two decades provides a comprehensive analysis of the state-of-art of digital technologies for safety management with a focus on the design stage. The review includes an evaluation of several different digital tools including BIM, AR, VR, and cloud computing for improving safety. Due to the evolution of ICT for the planning stage of construction, architects, designers and engineers play a major role as early adopters of ICT tools with new 
functionalities and are therefore at the forefront of new innovative practices. Despite the increasing usage of technologies such as BIM in the design and planning stages for clash detection, sequencing and quantities estimation, implementation of such technologies for PtD is still limited, though increasing. In this paper, a classification was proposed for different applications based on current digital technologies. The areas of application of digital technologies for PtD were classed as: knowledge base systems; automatic rule checking; hazard visualisation; and safety training for designers. Hazard visualisation is the most advanced area of application due to the capabilities of technologies such as $\mathrm{BIM}, \mathrm{AR}$, and VR, while the safety training for designers is the least matured area of application, as most of the studies in this area focus on construction workers and not designers. Thus, education and training of designers in PtD via the use of digital technologies requires attention from researchers. The development of such digital tools could benefit from integration of several technologies such as BIM, $\mathrm{AR}, \mathrm{VR}$, and gaming engines.

In addition to the four areas of application of digital technologies for PtD, three principal areas of challenge were identified regarding the application of digital technologies for PtD. These are: scalability; inadequate quality of design models; and construction sequencing. Regarding the issue of scalability of the digital technologies, it was observed from the review that most of the technologies in previous research concentrated on only one risk type (often falling from height) and have neglected other risks (e.g., health risks). The second challenge, which is related to the availability of the required information in building information models, is due to issues such as poor standardisation of modelling, and the third challenge is linked to the information on construction sequence and methods not being available during preconstruction stage. Considering the application areas and the challenges discussed, the current absence of the link between digital technologies and PtD which has been highlighted throughout this paper is addressed by proposing an integrated framework for enhancing the use of digital technologies for PtD. Based on the observed limitations, the authors limited the review on techniques and technologies adopted in PtD for Safety I approach and concluded some prominent future research directions for Safety I approach only. Further research and development work would be required to focus on developing integrated tools and applications covering the less developed aspects of the proposed framework as discussed above.

\section{Acknowledgement}

The researchers wish to extend appreciation to the Lloyd's Register Foundation for funding this research as part of the Discovering Safety Programme.

\section{References}

Akinlolu, M., Haupt, T.C., Edwards, D.J. and Simpeh, F. (2020), "A bibliometric review of the status and emerging research trends in construction safety management technologies", International Journal of Construction Management, available at:https://doi.org/10.1080/15623599.2020.1819584.

Albert, A., Hallowell, M.R., Kleiner, B., Chen, A. and Golparvar-Fard, M. (2014), "Enhancing Construction Hazard Recognition with High-Fidelity Augmented Virtuality", Journal of Construction Engineering and Management, Vol. 140 No. 7, p. 11.

Alsharef, A., Banerjee, S., Uddin, S.M., Albert, A. and Jaselskis, E. (2021), "Early Impacts of the COVID-19 Pandemic on the United States Construction Industry", International Journal of Environmental Research and Public Health, available at:https://doi.org/10.3390/ijerph18041559.

Araya, F. (2021), "Modeling working shifts in construction projects using an agent-based approach to minimize the spread of COVID-19", Journal of Building Engineering, Vol. 41, p. 102413.

Azmy, N. and Mohd Zain, A.Z. (2016), "The application of technology in enhancing safety and health 
aspects on malaysian construction projects", ARPN Journal of Engineering and Applied Sciences, Vol. 11 No. 11, pp. 7209-7213.

Behm, M. (2005), "Linking construction fatalities to the design for construction safety concept", Safety Science, Vol. 43 No. 8, pp. 589-611.

Behm, M. and Choon Hock, P. (2012), "Safe design of skyrise greenery in Singapore", Smart and Sustainable Built Environment, Vol. 1 No. 2, pp. 186-205.

Booth, A., Sutton, A. and Papaioannou, D. (2016), Systematic Approaches to a Successful Literature Review, Sage.

Cameron, I.T. (2000), "An interactive web-based decision support system for hazardous industry landuse planning”, Computers \& Chemical Engineering, Vol. 24 No. 2-7, pp. 1057-1062.

Carter, G. and Smith, S.D. (2006), "Safety hazard identification on construction projects", Journal of Construction Engineering and Management, Vol. 132 No. 2, pp. 197-205.

Che Ibrahim, C.K.I., Belayutham, S., Manu, P. and Mahamadu, A.-M. (2021), "Key attributes of designers' competency for prevention through design (PtD) practices in construction: a review", Engineering, Construction and Architectural Management, Emerald Publishing Limited, Vol. 28 No. 4, pp. 908-933.

Chi, N.W., Lin, K.Y. and Hsieh, S.H. (2014), "Using ontology-based text classification to assist Job Hazard Analysis", Advanced Engineering Informatics, Elsevier BV, Vol. 28 No. 4, pp. 381-394.

Chi, S., Han, S., Kim, D.Y. and Shin, Y. (2015), "Accident risk identification and its impact analyses for strategic construction safety management", Journal of Civil Engineering and Management, Vol. 21 No. 4, pp. 524-538.

Choe, S. and Leite, F. (2017), "Construction safety planning: Site-specific temporal and spatial information integration", Automation in Construction, Vol. 84, pp. 335-344.

Collinge, W., Manu, P., Cheung, C., Hadi Mosleh, M. and Farghaly, K. (2020), "Methodologies, strategies and interactions ", International Good Health, Wellbeing and Decent Work Conference (CIB W099 \&amp; TG59 2020), September.

Cooke, T. (2008), “ToolSHeDTM”, Engineering, Construction and Architectural Management, Vol. 15 No. 4, pp. 336-351.

Darko, A., Chan, A.P.C., Adabre, M.A., Edwards, D.J., Hosseini, M.R. and Ameyaw, E.E. (2020), "Artificial intelligence in the AEC industry: Scientometric analysis and visualization of research activities", Automation in Construction, Vol. 112, p. 103081.

Davis, K.A. and Songer, A.D. (2008), "Resistance to IT change in the AEC industry: an individual assessment tool".

Denyer, D. and Tranfield, D. (2009), "Producing a systematic review", The Sage Handbook of Organizational Research Methods, pp. 671-689.

Din, Z.U. and Gibson, G.E. (2019), "Serious games for learning prevention through design concepts: An experimental study", Safety Science, Vol. 115, pp. 176-187.

Ding, L.Y., Zhong, B.T., Wu, S. and Luo, H.B. (2016), "Construction risk knowledge management in BIM using ontology and semantic web technology", Safety Science, Elsevier BV, Vol. 87, pp. 202-213.

Eastman, C., Lee, J., Jeong, Y. and Lee, J. (2009), “Automatic rule-based checking of building designs", Automation in Construction, Vol. 18 No. 8, pp. 1011-1033.

Edirisinghe, R., Stranieri, A. and Blismas, N. (2016), "Information visualisation for the wicked problem 
of safe construction design", Architectural Engineering and Design Management, Vol. 12 No. 4, pp. $296-310$.

Farghaly, K. (2019), “Ontologies and Linked Data for structuring published BIM articles”, Proceedings of the 2019 European Conference for Computing in Construction, Crete, Greece, available at:https://doi.org/http://dx.doi.org/10.35490/EC3.2019.143.

Farghaly, K., Abanda, F.H., Vidalakis, C. and Wood, G. (2019), "BIM-linked data integration for asset management", Built Environment Project and Asset Management, Emerald, Vol. 9 No. 4, pp. 489502.

Fargnoli, M. and Lombardi, M. (2020), "Building Information Modelling (BIM) to Enhance Occupational Safety in Construction Activities: Research Trends Emerging from One Decade of Studies", BUILDINGS, Vol. 10 No. 6, available at:https://doi.org/10.3390/buildings10060098.

Gambatese, J.A., Behm, M. and Rajendran, S. (2008), "Designâ $\square^{\mathrm{TM}_{\mathrm{S}}}$ role in construction accident causality and prevention: Perspectives from an expert panel", Safety Science, Vol. 46 No. 4, pp. 675-691.

Ghaffarianhoseini, A., Tookey, J., Ghaffarianhoseini, A., Naismith, N., Azhar, S., Efimova, O. and Raahemifar, K. (2017), "Building Information Modelling (BIM) uptake: Clear benefits, understanding its implementation, risks and challenges", Renewable and Sustainable Energy Reviews, Vol. 75, pp. 1046-1053.

Golabchi, A., Han, S. and AbouRizk, S. (2018), "A simulation and visualization-based framework of labor efficiency and safety analysis for prevention through design and planning", Automation in Construction, Vol. 96, pp. 310-323.

Guo, H., Yu, Y. and Skitmore, M. (2017), "Visualization technology-based construction safety management: A review", Automation in Construction, Vol. 73, pp. 135-144.

Guo, H.L., Li, H. and Li, V. (2013), "VP-based safety management in large-scale construction projects: A conceptual framework", Automation in Construction, Vol. 34, pp. 16-24.

Hadikusumo, B.H.W. and Rowlinson, S. (2002), "Integration of virtually real construction model and design-for-safety-process database", Automation in Construction, Vol. 11 No. 5, pp. 501-509.

Hadikusumo, B.H.W. and Rowlinson, S. (2004), "Capturing safety knowledge using design-for-safetyprocess tool", Journal of Construction Engineering and Management, Vol. 130 No. 2, pp. 281289.

Hardison, D. and Hallowell, M. (2019), "Construction hazard prevention through design: Review of perspectives, evidence, and future objective research agenda", Safety Science, Elsevier BV, Vol. 120, pp. 517-526.

Hardison, D., Hallowell, M. and Littlejohn, R. (2020), "Does the format of design information affect hazard recognition performance in construction hazard prevention through design reviews?", Safety Science, Vol. 121, pp. 191-200.

Hare, B., Kumar, B. and Campbell, J. (2020), "Impact of a multi-media digital tool on identifying construction hazards under the UK construction design and management regulations", JOURNAL OF INFORMATION TECHNOLOGY IN CONSTRUCTION, Vol. 25, pp. 482-499.

Hossain, M.A., Abbott, E.L.S., Chua, D.K.H., Nguyen, T.Q. and Goh, Y.M. (2018), "Design-for-Safety knowledge library for BIM-integrated safety risk reviews", Automation in Construction, Vol. 94, pp. 290-302.

HSE. (2020), "Workplace fatal injuries in Great Britain", Health and Safety Executive, available at: https://www.hse.gov.uk/statistics/pdf/fatalinjuries-20.pdf.

Hsueh, S.L., Huang, C.F. and Tseng, C.Y. (2013), "Using data mining technology to explore labor 
safety strategy - A lesson from the construction industry", Pakistan Journal of Statistics, Vol. 29 No. 5, pp. 611-620.

Jin, Z., Gambatese, J., Liu, D. and Dharmapalan, V. (2019), "Using 4D BIM to assess construction risks during the design phase", Engineering, Construction and Architectural Management, available at:https://doi.org/10.1108/ecam-09-2018-0379.

Kamardeen, I. (2015), Fall Prevention through Design in Construction: The Benefits of Mobile Computing, Routledge.

Kasirossafar, M., Ardeshir, A. and Shahandashti, R.L. (2012), "Developing the sustainable design with PtD using 3D/4D BIM tools", World Environmental and Water Resources Congress 2012: Crossing Boundaries, pp. 2786-2794.

Kaushik, A., Kumar, S., Luthra, S. and Haleem, A. (2014), "Technology transfer: enablers and barriersa review", International Journal of Technology, Policy and Management, Vol. 14 No. 2, pp. $133-$ 159.

Kim, B., Kim, C. and Kim, H. (2012), "Interactive Modeler for Construction Equipment Operation Using Augmented Reality", Journal of Computing in Civil Engineering, Vol. 26 No. 3, pp. 331341.

Kim, I., Lee, Y. and Choi, J. (2020), "BIM-based Hazard Recognition and Evaluation Methodology for Automating Construction Site Risk Assessment", APPLIED SCIENCES-BASEL, Vol. 10 No. 7, available at:https://doi.org/10.3390/app10072335.

Kim, K., Cho, Y. and Kim, K. (2018), "BIM-Driven Automated Decision Support System for Safety Planning of Temporary Structures", Journal of Construction Engineering and Management, Vol. 144 No. 8, p. 4018072.

Kim, K. and Teizer, J. (2014), "Automatic design and planning of scaffolding systems using building information modeling", Advanced Engineering Informatics, Vol. 28 No. 1, pp. 66-80.

Kiviniemi, M., Sulankivi, K., Kähkönen, K., Mäkelä, T. and Merivirta, M.-L. (2011), "BIM-based safety management and communication for building construction".

Kumar, S.S. and Cheng, J.C.P. (2015), "A BIM-based automated site layout planning framework for congested construction sites", Automation in Construction, Vol. 59, pp. 24-37.

Lee, Y., Kim, I. and Choi, J. (2020), "Development of BIM-Based Risk Rating Estimation Automation and a Design-for-Safety Review System", APPLIED SCIENCES-BASEL, Vol. 10 No. 11, available at:https://doi.org/10.3390/app10113902.

Liang, H., Zhang, S. and Su, Y. (2020), "The structure and emerging trends of construction safety management research: a bibliometric review", INTERNATIONAL JOURNAL OF OCCUPATIONAL SAFETY AND ERGONOMICS, Vol. 26 No. 3, pp. 469-488.

Malekitabar, H., Ardeshir, A., Sebt, M.H. and Stouffs, R. (2016), "Construction safety risk drivers: A BIM approach", Safety Science, Vol. 82, pp. 445-455.

Mann III, J.A. (2008), "Education issues in prevention through design", Journal of Safety Research, Vol. 39 No. 2, pp. 165-170.

Manu, P., Gibb, A. and Behm, M. (2016), "New tool will help civil engineers meet CDM requirements to design for safety", Proceedings of the Institution of Civil Engineers: Civil Engineering, Vol. 170 No. 2, p. 55.

Manu, P., Poghosyan, A., Mahamadu, A.-M., Mahdjoubi, L., Gibb, A., Behm, M. and Akinade, O.O. (2019), "Design for occupational safety and health: key attributes for organisational capability", ENGINEERING CONSTRUCTION AND ARCHITECTURAL MANAGEMENT, Vol. 26 No. 11, SI, pp. 2614-2636. 
Megahed, N.A. and Ghoneim, E.M. (2021), "Indoor Air Quality: Rethinking rules of building design strategies in post-pandemic architecture", Environmental Research, Vol. 193, p. 110471.

Melzner, J., Zhang, S., Teizer, J. and BargstÃ adt, H.J. (2013), “A case study on automated safety compliance checking to assist fall protection design and planning in building information models", Construction Management and Economics, Vol. 31 No. 6, pp. 661-674.

Mohammadi, A., Tavakolan, M. and Khosravi, Y. (2018), "Factors influencing safety performance on construction projects: A review", Safety Science, Vol. 109, pp. 382-397.

Morrow, S., Cameron, I. and Hare, B. (2015), "The effects of framing on the development of the design engineer: Framing health and safety in design", Architectural Engineering and Design Management, Vol. 11 No. 5, pp. 338-359.

Moura, R., Beer, M., Patelli, E., Lewis, J. and Knoll, F. (2016), "Learning from major accidents to improve system design", Safety Science, Vol. 84, pp. 37-45.

O’Neill, M.M., Booth, S.R. and Lamb, J.T. (2018), "Using NVivoâ,„£ for literature reviews: The eight step pedagogy $(\mathrm{N} 7+1)$ ".

Park, C.S. and Kim, H.J. (2013), “A framework for construction safety management and visualization system", Automation in Construction, Vol. 33, pp. 95-103.

Park, J., Park, S. and Oh, T. (2015), "The development of a web-based construction safety management information system to improve risk assessment", Ksce Journal of Civil Engineering, Vol. 19 No. 3 , pp. 528-537.

Park, J.Y. and Park, Y.W. (2004), "Model-based concurrent systems design for safety", Concurrent Engineering-Research and Applications, Vol. 12 No. 4, pp. 287-294.

Pawson, R., Greenhalgh, T., Harvey, G. and Walshe, K. (2005), "Realist review-a new method of systematic review designed for complex policy interventions", Journal of Health Services Research \& Policy, Vol. 10 No. 1_suppl, pp. 21-34.

Przybyła, P., Brockmeier, A.J., Kontonatsios, G., Le Pogam, M.M., McNaught, J., von Elm, E., Nolan, K., et al. (2018), "Prioritising references for systematic reviews with RobotAnalyst: a user study", Research Synthesis Methods, Vol. 9 No. 3, pp. 470-488.

Qi, J., Issa, R.R.A., Olbina, S. and Hinze, J. (2014), "Use of Building Information Modeling in Design to Prevent Construction Worker Falls", Journal of Computing in Civil Engineering, Vol. 28 No. 5, p. 10.

Rodrigues, F., Antunes, F. and Matos, R. (2020), "Safety plugins for risks prevention through design resourcing BIM", Construction Innovation, available at:https://doi.org/10.1108/CI-12-2019-0147.

Sacks, R., Whyte, J., Swissa, D., Raviv, G., Zhou, W. and Shapira, A. (2015), "Safety by design: dialogues between designers and builders using virtual reality", Construction Management and Economics, Vol. 33 No. 1, pp. 55-72.

Santos, R., Costa, A.A. and Grilo, A. (2017), "Bibliometric analysis and review of Building Information Modelling literature published between 2005 and 2015", Automation in Construction, Vol. 80, pp. $118-136$.

Schupp, B., Hale, A., Pasman, H., Lemkovitz, S. and Goossens, L. (2006), "Design support for the systematic integration of risk reduction into early chemical process design", SAFETY SCIENCE, Vol. 44 No. 1, pp. 37-54.

Schwabe, K., Teizer, J. and König, M. (2019), “Applying rule-based model-checking to construction site layout planning tasks", Automation in Construction, Vol. 97, pp. 205-219.

Shen, T., Nagai, Y. and Gao, C. (2019), "Design of building construction safety prediction model based 
on optimized BP neural network algorithm", Soft Computing, available at:https://doi.org/10.1007/s00500-019-03917-4.

Su, Y.K., Yang, S.J., Liu, K.N., Hua, K.C. and Yao, Q. (2019), "Developing A Case-Based Reasoning Model for Safety Accident Pre-Control and Decision Making in the Construction Industry", International Journal of Environmental Research and Public Health, Vol. 16 No. 9, p. 20.

Sujan, M.A., Huang, H. and Braithwaite, J. (2017), "Learning from incidents in health care: Critique from a Safety-II perspective", Safety Science, Vol. 99, pp. 115-121.

Teizer, J. and Melzner, J. (2018), "BIM for Construction Safety and Health", Building Information Modeling, Springer International Publishing, Cham, pp. 349-365.

Teja Swaroop, D., Satish Chandra, D. and Asadi, S.S. (2018), "Application of safety and risk management techniques in construction using analytic hierarchy process (AHP) - A case study", International Journal of Civil Engineering and Technology, Vol. 9 No. 4, pp. 719-724.

Teo, A.L.E., Ofori, G., Tjandra, I.K. and Kim, H. (2016), "Design for safety: theoretical framework of the safety aspect of BIM system to determine the safety index", Construction Economics and Building, Vol. 16 No. 4, pp. 1-18.

Tixier, A.J.P., Hallowell, M.R., Rajagopalan, B. and Bowman, D. (2017), "Construction Safety Clash Detection: Identifying Safety Incompatibilities among Fundamental Attributes using Data Mining", Automation in Construction, Vol. 74, pp. 39-54.

Tymvios, N. (2017), "Design Resources for Incorporating PtD”, Practice Periodical on Structural Design and Construction, Vol. 22 No. 4, p. 6.

Vassie, L., Tomàs, J.M. and Oliver, A. (2000), "Health and Safety Management in UK and Spanish SMEs: A Comparative Study", Journal of Safety Research, Vol. 31 No. 1, pp. 35-43.

Vigneshkumar, C. and Salve, U.R. (2020), "A scientometric analysis and review of fall from height research in construction", Construction Economics and Building, Vol. 20 No. 1, pp. 17-35.

Wang, H.H., Boukamp, F. and Elghamrawy, T. (2011), "Ontology-Based Approach to Context Representation and Reasoning for Managing Context-Sensitive Construction Information", Journal of Computing in Civil Engineering, Vol. 25 No. 5, pp. 331-346.

Wang, J. and Ruxton, T. (1997), "A review of safety analysis methods applied to the design process", Journal of Engineering Design, Vol. 8 No. 2, pp. 131-152.

Xing, X., Zhong, B., Luo, H., Li, H. and Wu, H. (2019), “Ontology for safety risk identification in metro construction”, Computers in Industry, Vol. 109, pp. 14-30.

Yuan, J.F., Li, X.W., Xiahou, X.E., Tymvios, N., Zhou, Z.P. and Li, Q.M. (2019), “Accident prevention through design (PtD): Integration of building information modeling and PtD knowledge base", Automation in Construction, Vol. 102, pp. 86-104.

Zhang, S., Boukamp, F. and Teizer, J. (2015), "Ontology-based semantic modeling of construction safety knowledge: Towards automated safety planning for job hazard analysis (JHA)", Automation in Construction, Vol. 52, pp. 29-41.

Zhang, S.J., Sulankivi, K., Kiviniemi, M., Romo, I., Eastman, C.M. and Teizer, J. (2015), "BIM-based fall hazard identification and prevention in construction safety planning", Safety Science, Vol. 72, pp. 31-45.

Zhang, S.J., Teizer, J., Lee, J.K., Eastman, C.M. and Venugopal, M. (2013), "Building Information Modeling (BIM) and Safety: Automatic Safety Checking of Construction Models and Schedules", Automation in Construction, Vol. 29, pp. 183-195.

Zhang, W., Zhang, X., Luo, X. and Zhao, T. (2019), "Reliability model and critical factors identification 
of construction safety management based on system thinking", Journal of Civil Engineering and Management, Vol. 25 No. 4, pp. 362-379.

Zhang, W., Zhu, S., Zhang, X. and Zhao, T. (2019), "Identification of critical causes of construction accidents in China using a model based on system thinking and case analysis", Safety Science, available at:https://doi.org/10.1016/j.ssci.2019.04.038.

Zhou, Z.P., Li, C.Z., Mi, C.M. and Qian, L.F. (2019), "Exploring the Potential Use of Near-Miss Information to Improve Construction Safety Performance”, Sustainability, Vol. 11 No. 5, p. 21.

Zou, P.X.W., Lun, P., Cipolla, D. and Mohamed, S. (2017), "Cloud-based safety information and communication system in infrastructure construction", Safety Science, Vol. 98, pp. 50-69. 